\title{
Survival during treatment with tumour necrosis factor blocking agents in rheumatoid arthritis
}

\author{
M Flendrie, M C W Creemers, P M J Welsing, A A den Broeder, P L C M van Riel
}

Ann Rheum Dis 2003;62(Suppl II):ii30-ii33

Tumour necrosis factor (TNF) blocking agents are an important advance in the clinical treatment of rheumatoid arthritis (RA). They were introduced into clinical practice while limited safety information was available. This means that intensive monitoring is needed early in the life cycle of these new drugs. Setting up large cohort studies to monitor efficacy, safety, and tolerability in long term use of these so-called biological agents will provide information about the consequences of using TNF blocking agents in chronic rheumatic disease like RA. Currently, a Dutch multicentre registry on biological agents in RA is being set up. This study aimed at investigating the efficacy and toxicity of TNF blocking agents in patients with RA at one participating academic centre by a drug survival analysis. Since 1997230 patients with RA at the centre have been treated with TNF blocking agents for the first time (94 with adalimumab, 120 with infliximab, and 16 with etanercept). No differences in drug survival between the three TNF blocking agents were found despite the diversity in selection and patient numbers. Adverse events which occurred, leading to discontinuation, were similar to those from previous reports.

$\mathrm{T}$ hree tumour necrosis factor (TNF) blocking agents, etanercept (Enbrel), infliximab (Remicade), and adalimumab (Humira) are currently being used for the treatment of rheumatoid arthritis (RA). In clinical trials these so-called biological agents have been shown to be efficacious for the treatment of RA. ${ }^{1-3}$ No studies reported a significant increase in serious adverse events compared with placebo, and in open label extension trials the level of safety and tolerability was sustained. ${ }^{45}$

However, in daily clinical practice patients with RA may differ considerably-for example, in their comorbidity and concurrent drug treatment, from patients in randomised clinical trials. These differences may influence the efficacy and safety profile.

Reports from daily clinical practice are still limited, but a number of safety issues have arisen, like reactivation of tuberculosis (TB), demyelinating disease, drug induced systemic lupus erythematosus, opportunistic infections, and the risk for malignancies. ${ }^{6-9}$ These issues need further elucidation. Setting up large cohort studies to monitor long term efficacy and safety will provide information about the true incidence of these rare adverse events. At present a number of these registries on biological agents are being set up or have already started in countries world wide. In the process of setting up a Dutch registry, which will monitor all patients receiving biological agents in 10 rheumatology centres, data were collected on all patients with RA at our centre who had received TNF blocking agents since 1997. In this prospective study we investigated the survival during treatment with TNF blocking agents.

\section{PATIENTS AND METHODS}

All patients with RA, fulfilling the 1987 American College of Rheumatology criteria, ${ }^{10}$ who started treatment with adalimumab, infliximab, or etanercept before 1 January 2003 at the department of rheumatology of the University Medical Centre Nijmegen were identified. Patients receiving adalimumab had been treated in phase 1, 2, and 3 clinical trials. Adalimumab was given subcutaneously or intravenously at different dosages and intervals in several trials. After completion of the initial trial patients entered an open label extension study, in which they were treated with adalimumab $40 \mathrm{mg}$ subcutaneously every other week, with the possibility of a dose increase to $40 \mathrm{mg}$ weekly when high disease activity or exacerbation persisted. Patients receiving infliximab and etanercept were treated in daily clinical practice and fulfilled the Dutch criteria for TNF blocking therapy; had moderate to high disease activity, and high dosage methotrexate and at least one other disease modifying antirheumatic drug (DMARD) had failed. They started at standard dosing regimens (infliximab $3 \mathrm{mg} / \mathrm{kg}$ every eight weeks and etanercept $25 \mathrm{mg}$ twice a week).

Data collected were age, sex, disease duration, rheumatoid factor positivity and the number of previous DMARDs. At the start of the TNF blocking treatment data on 28 joint counts, erythrocyte sedimentation rate, visual analogue scale general health, prednisone dose, and the starting date of treatment were collected. If a patient discontinued TNF blocking treatment the date at which they stopped and the reason for discontinuation were collected. If a patient had received more than one TNF blocking agent only the initial treatment was used in the analysis. The disease activity score (DAS28) was used for assessment of disease activity. All data collected were entered into an electronic patient registry, consisting of an Access database, with a Visual Basic application (both Microsoft). This system, called POLIDAS, was developed in collaboration with the department of medical technology assessment of the University of Nijmegen for long term registration and monitoring of patients with RA.

\section{Statistical analysis}

Differences in baseline characteristics between the groups were studied using one way analysis of variance or $\chi^{2}$ if appropriate. Drug survival was estimated by lifetable analysis with 1 January 2003 as the censoring date. This was performed for each TNF blocking agent as well as for the total group. Drug survival between groups was compared using Wilcoxon (Gehan) statistics. Analyses were performed with SAS statistical software (version 8.0, SAS Institute Inc, USA), and SPSS statistical software (version 10.0, SPSS Inc, USA).

Abbreviations: DMARD, disease modifying antirheumatic drug; RA, rheumatoid arthritis; TB, tuberculosis; TNF, tumour necrosis factor 
Table 1 Baseline characteristics

\begin{tabular}{lllll}
\hline & $\begin{array}{l}\text { Adalimumab } \\
(\mathrm{n}=94)\end{array}$ & $\begin{array}{l}\text { Infliximab } \\
(\mathrm{n}=120)\end{array}$ & $\begin{array}{l}\text { Etanercept } \\
(\mathrm{n}=16)\end{array}$ & $\begin{array}{l}\text { Total group } \\
(\mathrm{n}=230)\end{array}$ \\
\hline Age (years), mean (SD) & $55.2(12.3)$ & $56.4(12.6)$ & $50.6(12.2)$ & $55.5(12.4)$ \\
Female, No (\%) & $59(63)$ & $86(72)$ & $10(63)$ & $155(67)$ \\
Weight (kg), mean (SD) & $71.2(12.5)$ & $74.5(13.6)$ & $70.6(9.6)$ & $72.7(12.8)$ \\
Disease duration (years), mean (SD) & $11.4(8.32)$ & $11.9(8.9)$ & $10.1(10.5)$ & $11.6(8.7)$ \\
RF positivity, No (\%) & $87(93)$ & $98(82)$ & $14(88)$ & $199(87)$ \\
Previous DMARD use, mean (SD) & $4.5(1.8)$ & $4.1(1.6)$ & $3.3(1.7)$ & $4.2(1.8)$ \\
Patients receiving prednisone, No (\%) & $48(51)^{*}$ & $29(24)$ & $3(19)$ & $80(35)$ \\
DAS28 at start, mean (SD) & $6.4(1.1)^{*}$ & $5.9(1.1)$ & $5.8(1.5)$ & $6.1(1.1)$ \\
\hline${ }^{*} \mathrm{p}<0.05$ & & & & \\
\hline
\end{tabular}

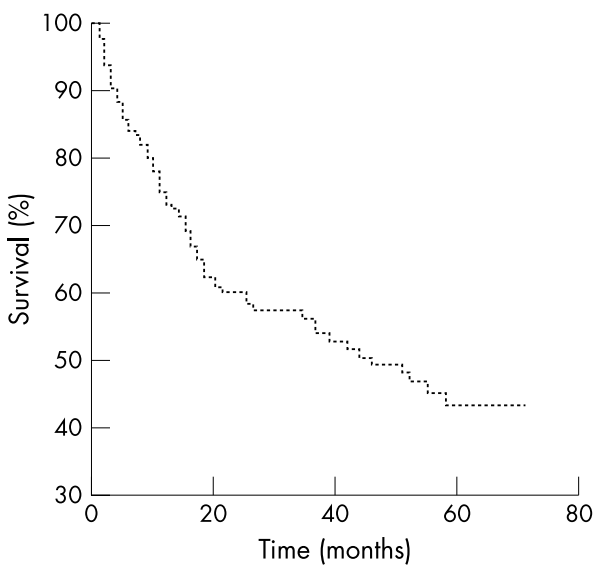

Figure 1 Drug survival for the total group.

\section{RESULTS}

Two hundred and thirty patients with RA were identified: 94 had started adalimumab treatment between April 1997 and September 2000; 120 patients had started infliximab since January 2000; and 16 had started etanercept since February 2000. Table 1 shows the baseline characteristics of the groups. No statistically significant differences in baseline characteristics were found, except for a significantly higher mean DAS28 at the start and a larger number of patients receiving steroids in the adalimumab group.

Figure 1 shows the drug survival for the total group of 230 patients with RA. The median survival time was 37 months. Maximum follow up time for adalimumab, infliximab, and etanercept was 69, 35, and 30 months, respectively. Figure 2 shows the drug survival curves for the three TNF blocking agents. One year survival percentages were $73 \%$ for adalimumab, $66 \%$ for infliximab, and $74 \%$ for etanercept. No significant differences in survival between the groups were found.

Table 2 shows the reasons for discontinuation within the first year of TNF blocking therapy. Table 3 lists the adverse events which led to discontinuation within the first year of TNF blocking therapy.

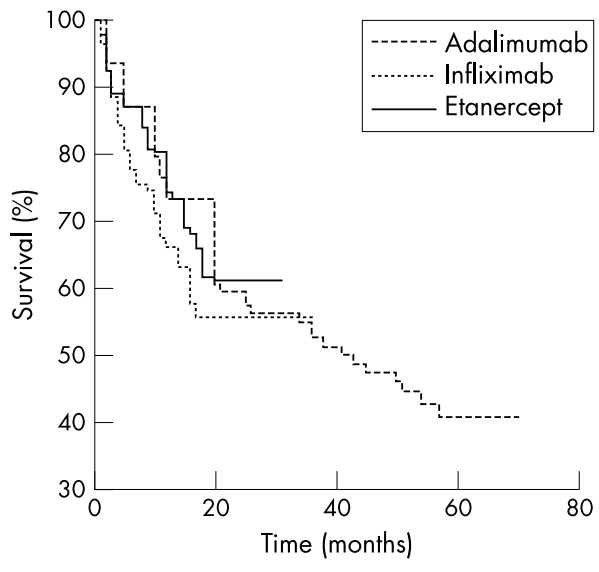

Figure 2 Drug survival for each TNF blocking agent.

Allergic reactions all occurred in patients given intravenous TNF blocking therapy; observed symptoms were hypotension, hypertension, flushing, dyspnoea, cyanosis, urticaria, and pruritus. Twelve patients stopped TNF blocking agents because of infections, seven of them within the first year (table 4). Reactivation of TB was seen in two patients. One patient had started TNF blocking therapy at a time when screening for TB was not yet implemented and the other patient developed TB despite screening. Malignancies occurred in six cases: one metastatic mamma carcinoma, one cutaneous cell carcinoma, one non-Hodgkin's lymphoma, one metastatic prostate carcinoma, one oat cell carcinoma, and one patient developed a squamous cell carcinoma of the oesophagus and hepatic metastases of an adenocarcinoma of unknown origin (the last four patients died).

\section{CONCLUSION AND DISCUSSION}

We investigated drug survival of three TNF blocking agents in a group of patients with active, longstanding RA. About $70 \%$ of the patients still were receiving TNF blocking therapy after the first year. No significant differences in survival were seen between patients receiving different agents despite the diversity of patient selection and patient numbers in the groups.

\begin{tabular}{|c|c|c|c|c|}
\hline & $\begin{array}{l}\text { Adalimumab } \\
(\mathrm{n}=94) \text { No }(\%)\end{array}$ & $\begin{array}{l}\text { Infliximab }(n=83) \\
\text { No }(\%)\end{array}$ & $\begin{array}{l}\text { Etanercept }(n=14) \\
\text { No }(\%)\end{array}$ & $\begin{array}{l}\text { Total }(n=191) \\
\text { No }(\%)\end{array}$ \\
\hline Inefficacy & $10(11)$ & $8(10)$ & $1(7)$ & $19(10)$ \\
\hline Adverse events & $10(11)$ & $20(24)$ & $1(7)$ & $31(16)$ \\
\hline Combination & 1 (1) & $5(6)$ & $0(0)$ & $6(3)$ \\
\hline Other* & $3(3)$ & $2(2)$ & $2(14)$ & $7(4)$ \\
\hline Total & $24(26)$ & $35(42)$ & $4(29)$ & $63(33)$ \\
\hline
\end{tabular}


Table 3 Adverse events as reason for discontinuation within the first year

\begin{tabular}{lcccc}
\hline & $\begin{array}{l}\text { Adalimumab } \\
(n=94)\end{array}$ & $\begin{array}{l}\text { Infliximab }(\%) \\
\text { No }(\%)\end{array}$ & $\begin{array}{l}\text { Etanercept }(n=14) \\
\text { No }(\%)\end{array}$ & $\begin{array}{l}\text { Total }(n=191) \\
\text { No }(\%)\end{array}$ \\
\hline Infusion reactions & $3(3)$ & $12(14)$ & $0(0)$ & $15(8)$ \\
Skin rashes & $1(1)$ & $3(4)$ & $0(0)$ & $4(2)$ \\
Infections & $2(2)$ & $5(6)$ & $0(0)$ & $7(4)$ \\
Malignancies & $2(2)$ & $0(0)$ & $0(0)$ & $2(1)$ \\
Cardiac disease & $3(3)$ & $0(0)$ & $0(0)$ & $3(2)$ \\
SLE-like disease & $0(0)$ & $2(2)$ & $0(0)$ & $4(2)$ \\
Other* & $0(0)$ & $3(4)$ & $1(7)$ & $37(19)$ \\
Total & $11(12)$ & $25(30)$ & $1(7)$ & \\
\hline \multirow{2}{*}{ *Other serious adverse events were dyspnoea, dermatomyositis, reversible leucopenia, and nausea. }
\end{tabular}

Table 4 Serious infections

\begin{tabular}{lllllll}
\hline $\begin{array}{l}\text { Age } \\
\text { (years) }\end{array}$ & Sex & $\begin{array}{l}\text { Disease } \\
\text { duration (years) }\end{array}$ & $\begin{array}{l}\text { TNF blocking } \\
\text { agent }\end{array}$ & $\begin{array}{l}\text { Duration of } \\
\text { anti-TNF (months) }\end{array}$ & Comedication & Infection \\
\hline 62 & M & 27.4 & Adalimumab & 5 & Prednisone & Sepsis (S aureus) \\
48 & $\mathrm{~F}$ & 23.4 & Adalimumab & 8 & - & Infected hip prosthesis (S epidermidis) \\
63 & $\mathrm{~F}$ & 7.1 & Adalimumab & 12 & Prednisone & Peptic arthritis knee (Salmonella spp) \\
38 & $\mathrm{~F}$ & 11.3 & Adalimumab & 16 & - & Persisting subaxillary abscess \\
50 & $\mathrm{~F}$ & 15.1 & Adalimumab & 35 & Prednisone & Pecurrent pustulosis (S aureus) \\
49 & $\mathrm{M}$ & 9.3 & Adalimumab & 52 & Prednisone & Ulmonary TB \\
75 & $\mathrm{~F}$ & 5.1 & Infliximab & 3 & Sulfasalazine, prednisone & Perforated appendicitis \\
43 & $\mathrm{M}$ & 18.9 & Infliximab & 3 & Prednisone & Infected leg ulcer \\
68 & $\mathrm{~F}$ & 7.2 & Infliximab & 4 & Leflunomide & Persisting tooth abscess \\
53 & $\mathrm{~F}$ & 9.5 & Infliximab & 4 & Prednisone & Pulmonary TB (deceased) \\
64 & $\mathrm{M}$ & 12.5 & Infliximab & 8 & Methotrexate prednisone & Septic arthritis shoulder and hip (S aureus) \\
71 & $\mathrm{~F}$ & 20.0 & Infliximab & 26 & &
\end{tabular}

The survival percentages do not show any great differences from those of other reports. The South Sweden Arthritis Research Group reported a 20 month drug survival of $79 \%$ in 166 patients with RA receiving etanercept and 75\% in 135 patients with RA receiving infliximab. ${ }^{11}$ In a Spanish registry of biological agents the survival was $86 \%$ after 12 months in a combined group of 1309 patients (1070 RA) receiving 1172 treatment courses of infliximab and 164 of etanercept. ${ }^{12}$

Also, reasons for discontinuation reported in this study are similar to those given in previous reports. ${ }^{13511}$ Inefficacy and adverse events were encountered in equal numbers for the adalimumab and etanercept group. In the infliximab group adverse events were relatively more often a reason for discontinuation. This might be explained by the number of infusion reactions. We did not perform a statistical comparison on the reasons for discontinuation between the groups because this was considered inappropriate: firstly, because of the differences in patient selection. Patients receiving adalimumab were treated in the first clinical trials with this agent, in a period when there were fewer other treatment options. This group had more severe RA, indicated by a higher mean disease activity at the start and a larger number of patients receiving steroids. These factors could influence drug survival. Secondly, the small number of patients receiving etanercept, because of the scarcity of this drug in the Netherlands, limits a direct comparison with the other agents studied.

All serious adverse events encountered have been reported in previous studies, with the exception of dermatomyositis. ${ }^{1351113}$ Infections, both minor recurrent and major infections requiring admission to hospital, were reasons for discontinuation within the first year in 7/191 (4\%) patients. All these patients had longstanding RA and most of them were treated with immunosuppressive drugs simultaneously. This rate is comparable with other reports on TNF blocking agents. ${ }^{15^{11} 14}$ Six malignancies of different origin were seen in this group.
Although an increased incidence of malignancies-for example, lymphoma, might be expected in theory, ${ }^{9}$ the number of cases seen was small. This might be attributed to the short period of treatment with TNF blocking agents, the relatively short duration of follow up, or the small number of patients.

It remains to be determined whether treatment with TNF blocking agents leads to an increased incidence of major infections and malignancies and rare adverse events. To gain more insight it is necessary to study larger groups of patients during a longer period of follow up. Merging data from registries which monitor toxicity and efficacy of TNF blocking agents could provide such information. Furthermore, it would enable a study of possible risk factors for serious adverse events. This implies a joint effort of rheumatologists, industry, and regulatory authorities. Recently a multicentre registry has been set up in the Netherlands. In parallel, several European rheumatology departments are cooperating to set up a European registry on biological agents. We strongly encourage such an effort because it would be an important step towards increasing knowledge about the long term safety and tolerability of current and future biological therapies in clinical practice.

\section{ACKNOWLEDGEMENTS}

We thank Aatke van der Mij for collecting some of the data presented in this study.

\section{Authors' affiliations}

M Flendrie, M C W Creemers, P M J Welsing, A A den Broeder, P L C M van Riel, UMC Nijmegen, The Netherlands

Correspondence to: Professor P L C M van Riel, UMC Nijmegen, PO Box 9101, Nijmegen, 6500 HB, The Netherlands; p.vanriel@reuma.umcn.nl 


\section{REFERENCES}

1 Lipsky PE, van der Heijde DM, St Clair EW, Furst DE, Breedveld FC, Kalden JR, et al. Infliximab and methotrexate in the treatment of rheumatoid arthritis. Anti-Tumor Necrosis Factor Trial in Rheumatoid Arthritis with Concomitant Therapy Study Group. N Engl J Med 2000;343:1594-602.

2 Moreland LW, Schiff MH, Baumgartner SW, Tindall EA Fleischmann RM, Bulpitt KJ, et al. Etanercept therapy in rheumatoid arthritis. A randomized, controlled trial. Ann Intern Med 1999;130: 478-86.

3 Weinblatt ME, Keystone EC, Furst DE, Moreland LW, Weisman MH, Birbara CA, et al. Adalimumab, a fully human anti-tumor necrosis factor alpha monoclonal antibody, for the treatment of rheumatoid arthritis in patients taking concomitant methotrexate: the ARMADA trial. Arthritis Rheum 2003;48:35-45.

4 Burmester GR, van de Putte L B, Rau R, Breedveld FC, Kalden JR, Malaise $M$, et al. Long term efficacy and safety of adalimumab monotherapy in patients with DMARD-refractory RA - results from a two year study [abstract]. Arthritis Rheum 2002;46(suppl): S537

5 Moreland LW, Cohen SB, Baumgartner SW, Tindall EA, Bulpitt K, Martin $\mathrm{R}$, et al. Long-term safety and efficacy of etanercept in patients with rheumatoid arthritis. J Rheumatol 2001;28:1238-44.

6 Day R. Adverse reactions to TNF-alpha inhibitors in rheumatoid arthritis. Lancet 2002;359:540-1.
7 Furst DE, Breedveld FC, Kalden JR, Smolen JS, Antoni CE, Bijlsma JW, et al. Updated consensus statement on biological agents for the treatment of rheumatoid arthritis and other rheumatic diseases (May 2002). Ann Rheum Dis 2002;61 (suppl II):ii2-7.

8 Weisman MH. What are the risks of biologic therapy in rheumatoid arthritis? An update on safety. J Rheumatol Suppl 2002;65:33-8.

9 Brown SL, Greene MH, Gershon SK, Edwards ET, Braun MM. Tumor necrosis factor antagonist therapy and lymphoma development: necrosis factor antagonist therapy and lymphoma development: Rheum 2002;46:3151-8.

10 Arnett FC, Edworthy SM, Bloch DA, McShane DJ, Fries JF, Cooper NS, et al. The American Rheumatism Association 1987 revised criteria for the classification of rheumatoid arthritis. Arthritis Rheum 1988:31:315-24.

11 Geborek P, Crnkic M, Petersson IF, Saxne T. Etanercept, infliximab, and leflunomide in established rheumatoid arthritis: clinical experience using a structured follow up programme in southern Sweden. Ann Rheum Dis 2002;61:793-8.

12 Cientifico BIOBADASER C. Spanish experience with a registry of adverse events on biological therapy. Ann Rheum Dis 2003;61 (suppl I):S388.

13 Maini R, St Clair EW, Breedveld F, Furst D, Kalden J, Weisman M, et al. Infliximab (chimeric anti-tumour necrosis factor alpha monoclonal antibody) versus placebo in rheumatoid arthritis patients receiving concomitant methotrexate: a randomised phase III trial. ATTRACT Study Group. Lancet 1999:354:1932-9.

14 Phillips K, Husni ME, Karlson EW, Coblyn JS. Experience with etanercept in an academic medical center: are infection rates increased? Arthritis Rheum 2002;47:17-21. 